\title{
Ethnothanasie et culture
}

\section{Raymond Mayer}

\section{OpenEdition}

\section{Journals}

Édition électronique

URL : https://journals.openedition.org/pa/1899

DOI : 10.4000/pa.1899

ISSN : 2273-0362

\section{Éditeur}

Université Lumière Lyon 2

\section{Édition imprimée}

Date de publication : 1 janvier 2006

Pagination : 40-53

ISBN : 1643-7706

ISSN : 1634-7706

\section{Référence électronique}

Raymond Mayer, «Ethnothanasie et culture », Parcours anthropologiques [En ligne], 6 | 2006, mis en ligne le 06 juillet 2021, consulté le 21 juillet 2021. URL : http://journals.openedition.org/pa/1899 ; DOI : https://doi.org/10.4000/pa.1899 


\title{
EthNothanAsie et Culture
}

\author{
Raymond Mayer \\ Université de Libreville (Gabon)
}

L'ethnogenèse appelle normalement une réflexion sur son symétrique qui serait quelque chose comme l'ethnothanasie. Il est obligatoire de se donner une théorie de la disparition des "ethnies ", ne serait-ce que pour parachever la formalisation de celle qui pense leur genèse. C'est l'exact propos de cet article. Paradoxalement, la "mort des ethnies » ne préoccupe guère la profession anthropologique, sinon sous sa forme violente stigmatisée par un Robert Jaulin (1970) sous le terme « ethnocide ", quand ce n'est pas sous la forme extrême du génocide (Franche, 1995; Amselle, 2001). En dehors de la profession, la «mort des civilisations " hante cependant, au moins depuis un siècle, certains littérateurs et s'est même trouvé des slogans médiatiques pour l'époque, telles les prédictions lancée par un Paul Valéry (1919) « Nous, civilisations, savons maintenant que nous sommes mortelles! » ou attribuée à un André Malraux (1965) « Le XXI ${ }^{\mathrm{e}}$ siècle sera religieux ou ne sera pas ${ }^{27}$ auxquelles répond la formule non moins mythique de Marc Augé « Le xxI siècle sera anthropologique » $(1991,55)$ !

$\mathrm{La}$ «mort des langues » mobilise de son côté foule de chercheurs; des programmes de "langues en danger ${ }^{28}$ voient le jour sans que l'on pressente l'équivalent chez les anthropologues. Il n'y a pas de groupe de défense systématique des "ethnies " sinon de manière marginale et plutôt sous les formes nouvelles de «l'autochtonie » (Morin, 2005) : n'est-ce pas l'aveu théorique de leur caractère inessentiel? Le but de cet article n'est pas d'en appeler au volontarisme d'une profession se chargeant de "sauver le soldat Ryan ", mais de déployer l'ensemble des conceptions théoriques qui en sous-tendent la pratique, et en l'occurrence la nonpratique.

Il y a, dans la perspective que je développe ici, trois ou quatre théories possibles pour produire l'ethnothanasie : soit on liquéfie l'« ethnie " de manière théorique, soit on la gorge de déterminismes historiques, soit on en prédit la disparition obligatoire à moyen terme. Pour ma part, j'envisagerai le cycle complet d'une vie et mort d'ethnie pour essayer

\footnotetext{
${ }^{27}$ Expression qui lui a été attribuée sans que l'on soit sûr qu'il l'ait dite.

${ }^{28}$ Programme coordonné à DDL (UMR 5596 CNRS-Lyon2) par Colette Grinevald et Lolke Van der Veen.
} 
d'en repérer les facteurs déterminants à chaque étape de ses processus lourds de transformation. En finale, je considérerai l'ethnothanasie comme une transformation consentie et non violente de l'ethnie en une culture, en " territorialisant " l'un et l'autre termes, à rebours des théories dominantes (Barth, 1969; Amselle \& Elikia-M'Bokolo, 1985; Amselle, 1990; Appadurai, 1996) qui plaident, depuis plus d'un quart de siècle, pour leur " déterritorialisation ». Pour y prétendre, ma contribution se fonde sur l'évolution accélérée observée pendant trente ans en Afrique centrale sur le terrain gabonais (1976-2006). Elle fait aussi référence à une situation de terrain polynésien - spécifiquement aux îles Wallis et Futuna - envisagée à trente-cinq ans d'intervalle (1971-2006). Elle voudrait enfin associer deux mille ans de terrain virtuel - celui de la France - comportant en filigrane la transformation des Gaules ethniques en une entité nationale. Ces trois exemples serviront de terrain référent à chaque étape théorique envisagée.

\section{THÉORIES NÉGATIVANTES DE L'ETHNIE}

Relèvent de la première tendance théorique lourde, tous les essais qui vont jusqu'à mettre en cause l'existence conceptuelle de l'ethnie. À son climax, cette position amène à la négation de l'ethnie. C'est en toutes lettres la position qu'indexe Jean-Pierre Digard (1993) rendant compte de l'ouvrage Logiques métisses de Jean-Loup Amselle (1990) : " Les ethnies, les nations font recette. Des articles et des livres leur sont plus que jamais consacrés [...] Or c'est précisément le moment que choisit Jean-Loup Amselle pour prétendre qu'elles n'existent pas! » La thèse en question pourrait être qualifiée de "négationniste » si le qualificatif n'était déjà prisonnier de son emploi polémique. Je la résume sous la forme d'un constat réduisant une hypothétique définition de l'ethnie à sa plus simple expression : l'ethnie était au mieux une illusion théorique qui a fini par apparaître comme telle, et qui a donc abouti à son autoélimination. Ce qui n'a jamais existé a disparu. L'explication vient de la posture théorique qui fait de «l'ethnie » un objet d'étude labile et finalement inexistant. Enterrer l'inexistant est la conséquence radicale d'une position cohérente assumée de bout en bout.

Une variante de cette dénégation de l'ethnie originelle existe dans son avatar colonial. On remarquera ainsi que dans la Guerre des Gaules (admirons le pluriel), le Romain César constitue en "tribus » tout ce qui n'est pas romain : la tribu des Trevisi, des Parisii, des Helvètes, des Burgondes, etc. Tout est tribu, sauf Rome. Les colonisateurs, des XV au XIX ${ }^{e}$ siècle, emprunteront la même catégorisation à propos des peuples d'Amérique, d'Afrique, d'Asie et d'Océanie. Tout est tribu, sauf la capitale d'Empire. Dès qu'un État colonisateur intervient dans un territoire non colonisé, ce dernier est affublé du lexique ethnique et tribal. Autrement dit, c'est la centralisation qui produit la balkanisation de la pensée externe. Comme par hasard, en grec, phulê désigne la «tribu ». La phylogenèse désigne ainsi la naissance de la tribu, au singulier ou 
au pluriel. La théorie de l'ethnie - que l'on me permette de traiter ici l'ethnie comme synonyme de la tribu césarienne - en tant que pure projection d'une pensée occidentale colonisatrice sur un monde colonisé trouverait là quelque fondement. Sur le terrain asiatique, Alexandra David-Néel (1953:1084) ne dit pas autre chose en écrivant qu'« au VII et $\mathrm{au}$ VIII ${ }^{\mathrm{e}}$ siècles, à l'époque de leur gloire militaire, les Tibétains étaient divisés en une centaine de tribus sans liens permanents et maintes fois en guerre les unes contre les autres".

Dans le contexte gabonais de la transformation des clans et lignages, j'avais noté en 1992 que « Les ethnies sont des inventions du $\mathrm{XX}^{\mathrm{e}}$ siècle, en ce sens qu'elles font oublier que les relations de famille se constituaient indépendamment des frontières ethniques, si tant est qu'on puisse parler de frontières. On n'a jamais vu, sur le terrain, d'ethnie se présenter globalement face à une autre ethnie. Sur le terrain, on ne voit que des sociétés lignagères. Ce sont les États centralisés modernes qui ont tendance à raisonner en termes d'ethnies et en grands ensembles à leur image. " (Mayer, 1992 :36) Ce qui est affirmé ici à partir de l'expérience gabonaise, c'est que l'ethnie est créée par un État colonial ou un État postcolonial. Dans ce dernier cas, l'État indépendant continue à gérer tout ce qui n'est pas lui, comme des ethnies et des tribus à unifier sous la bannière étatique.

À Wallis et Futuna, ce sont des constructions linguistiques qui positionnent des entités respectivement dénommées East 'Uvea et West 'Uvea, ainsi que East Futuna et West Futuna. Le caractère ethnique de ces entités n'est pas démontré. East 'Uvea en est venu à désigner aujourd'hui la langue pratiquée à l'île Wallis située au nord-est de l'archipel des Fidji. West 'Uvea, de son côté, correspond à une langue qui s'est formée dans l'île Ouvéa, partie des îles Loyautés, constituées depuis les accords de Matignon de 1990 en «troisième province » du territoire français d'Outre-mer de la Nouvelle-Calédonie. De même, East Futuna dénomme la langue de l'île jumelle du binôme Wallis-et-Futuna. Enfin West Futuna se réfère à une île méridionale de l'archipel des Vanuatu (anciennement Nouvelles-Hébrides).

Ainsi, que ce soit dans la Gaule romaine, en Afrique coloniale ou dans un archipel polynésien sous tutelle occidentale, et que ce soit pour des raisons de politique centralisatrice opposable à des entités décentralisées, ou pour des raisons linguistiques, l'anthropologie en arrive dans les trois cas à nier l'existence d'une substance qui serait d'essence " ethnique ». Cette première position est théoriquement cohérente, à condition d'avoir expliqué pourtant pourquoi on a fait scientifiquement usage d'un concept pendant plus d'un siècle sans se rendre compte qu'il s'agissait d'un mirage conceptuel. Dans ce contexte théorique, le terme " ethnie » est condamné, du moins dans le lexique francophone de l'ethnologie (puisque tribe a survécu à toutes les vicissitudes de l'évolution lexicographique anglo-saxonne), à vieillir au Xxi ${ }^{\mathrm{e}}$ siècle dans les mêmes conditions que le terme " tribu » a vieilli au $\mathrm{xx}^{\mathrm{e}}$ siècle. 


\section{THÉORIE HISTORICISTE DE L'ETHNIE}

Une tendance alternative consiste à reconnaître l'existence des ethnies, mais en en subordonnant le concept à ses déterminismes historiques. Relèvent de cette deuxième tendance théorique tous les essais visant à déconstruire la substantialisation de l'ethnie pour lui substituer une conception historique de ses constituants, et donc une dynamique interne largement aléatoire, contingente et imprévisible, puisque assujettie à l'histoire (avec ' $h$ ' majuscule ou minuscule). Cette tendance théorique pourrait être qualifiée d'historiciste.

En France, l'ouvrage emblématique de cette prise de position reste $L e$ coeur de l'ethnie, publié sous la direction de Jean-Loup Amselle ${ }^{29}$ et Elikia M'bokolo (1985). Dans cette posture, l'ethnie existe bien, et les auteurs l'ont bien rappelé au moment de la deuxième édition de l'ouvrage, au tournant de l'an 2000. C'est, au départ et à l'arrivée de la dynamique des transformations sociales, un concept incontournable. Cette théorie ne nie pas son existence, mais elle la subordonne à une autre théorie qui n'est pas forcément seulement celle de l'histoire. Joseph Tonda (1999) explicite bien ce point de vue quand il désubstantialise l'ethnie. Pour lui, l'imaginaire de l'ethnie s'impose à l'espace de l'ethnie.

Dans le cas de la France, on peut construire une culture «territoriale » en ses composantes ethniques (et maintenant provinciales) comme résultat d'un processus complexe propre à donner au concept « ethnique » les contenus que lui a forgés l'histoire. Les substances ethniques ne sont autres que celles de l'histoire. Dans un article sur la Gaule romaine, Philippe Testard-Vaillant (2003:158-160) considère qu'il ne reste des cultures gauloises qu'un " héritage insignifiant » et que "lune, forêt, druide " ne sont que « de pures créations du préromantisme qui n'ont rien de gaulois ». Le même, relayant d'autres spécialistes du domaine, précise qu'il n'existait pas une culture gauloise unique, mais une pluralité de cultures disposant de "quelques grands traits communs : le fait, par exemple, qu'ils étaient des agriculteurs et des éleveurs hors pair ». Bref, si ethnies et tribus il y eut, leur contenu s'est transformé au cours de l'histoire et a été modifié par l'histoire, mais il y a fort à parier qu'il n'y a pas d'autre contenu permanent ou variant que celui qui lui est conféré par les aléas ou les déterminismes de l'histoire.

Pendant ce temps, en Océanie, les îles Wallis et Futuna sont devenues successivement un protectorat français (1888-1961) et un territoire français d'Outre-Mer (à partir de 1961) - dans le jargon administratif : un том. Qu'est-ce à dire? Le statut politique conféré par l'État français aux îles Wallis et Futuna en a fait l'équivalent d'une sous-préfecture, où «l'Administrateur supérieur " (sic) représente l'exécutif de la métropole, et où les rois traditionnels (un à Wallis, 10000 habitants, et deux à Futuna, 5000 habitants) siègent au conseil de gouvernement du territoire qui dispose aussi d'une assemblée territoriale à compétence locale (Mayer, 1976 :44-45). Ce qu'il faut comprendre, c'est que la maîtrise

${ }^{29}$ Dans une position de principe qui précède celle de Logiques métisses (1990). 
locale du pouvoir politique est partiellement maintenue au sein de la chefferie traditionnelle, compétente en juridiction coutumière pour juger des délits non criminels et disposant surtout de la compétence exclusive en matière foncière. En résumé, l'histoire a inventé à Wallis et Futuna depuis quarante ans un système politique dyadique, où le pouvoir de l'État n'a pas forcément le dernier mot, quand bien même tous les Wallisiens et Futuniens sont devenus citoyens français après référendum (1959). Sur le plan religieux, le catholicisme introduit dans les îles par des missionnaires lyonnais à partir de 1837 a produit une révolution des croyances et des rites comparable aux effets d'une mondialisation avant l'heure. Dans d'autres îles du Pacifique (Firth, 1936 et 1959; Godelier, 1986), des transformations identiques, malgré des variantes dans les obédiences confessionnelles ou les subordinations politiques introduites, ont affecté durablement les « ethnies " insulaires par la force de l'histoire. L'ethnie, si elle subsiste, a pris les couleurs de l'histoire.

Enfin, sur le théâtre africain, nombre de colonies françaises de l'Afrique équatoriale française ou de l'Afrique occidentale française sont devenues indépendantes, ou dans un langage plus soutenu, ont acquis leur "souveraineté internationale ». Mais l'État colonial avait préalablement revendiqué la possession de la quasi-totalité des terres " ethniques ", en s'instaurant seule instance domaniale et en déclarant notamment " terres vacantes " tous les espaces en dehors des villages habités. Au Gabon, dès 1896, en raison des coûts d'entretien de l'administration coloniale, l'ensemble du territoire a été cédé à trois « sociétés concessionnaires »- sociétés commerciales françaises privées - qui y avaient les pleins pouvoirs (l'exercice de la violence légitime) pour réquisitionner terres et habitants. Cette situation peut de surcroît être interprétée comme le premier exemple d'administration totalement privatisée d'un territoire "national ». À l'indépendance, les ethnies ont été de fait fondues dans les nouveaux États-nations, même si les langues " ethniques » et les territoires villageois ont subsisté jusqu'à la période actuelle. Là encore, l'histoire a fait son œuvre au sein d'ethnies qui ont " historiquement » perdu leur prérogative principale, à savoir la gestion des droits du sol.

\section{THÉORIE ÉVOLUTIONNISTE DE L'ETHNIE}

Enfin troisième tendance théorique lourde qui apparaît comme la fille de la précédente, mais qui s'en distingue par le caractère irréversible de sa dynamique interne : "l'ethnie » serait une notion provisoire et transitoire qui ne résiste pas à l'évolution humaine. C'est un schéma globalement évolutionniste. L'ethnie est un archaïsme condamné à évoluer, comme l'était dans la langue française le terme "tribu » au début du XX $x^{\mathrm{e}}$ siècle, appelé à se transformer en un autre mot. Là encore, il n'est pas seulement question de mots, mais aussi de substance. L'ethnologie contemporaine a en quelque sorte fait le deuil a priori de sa matière éponyme et de sa discipline, au point de songer aux programmes de 
l'après-ethnie, avant même que la prédiction de la disparition de l'ethnie soit consommée.

Dans ce cadre théorique, les « imaginaristes » de la mondialisation n'ont aucun scrupule à déclarer la mort des ethnies et même à annoncer celle des États (sauf curieusement de l'État américain). Dans Appadurai (1996 : 75-77), on voit bien que l'ethnoscape s'est noyé dans un ensemble hétéroclite de mediascapes, de technoscapes, de financescapes et d'ideoscapes, le tout renvoyant au maëlstrom des "flux globaux ». Il faudrait strictement traduire ethnoscape par « ethnopanorama », pour montrer l'espèce de cinémascope macro-anthropologique auquel on est parvenu. Dans cette évolution irréversible, on peut sans doute s'étonner qu'il ne manque que les economicoscapes, c'est-à-dire les instances globalisantes, par rapport à des instances vues comme globalisées. Sur ce modèle, les Cultural Studies deviennent une norme applicable à l'export, par rapport au terrain américain dont elles sont issues. L'ethnisme est la dernière trace d'un ideoscape qui se fonde sur une théorie évolutionniste de l'ethnie.

Il reste à savoir quels sont les facteurs de disparition. On connaît la position de Claude Lévi-Strauss $(1952,1973)$ instituant une théorie d'une sorte de "struggle for [ethnic] life ", où les plus forts l'emportent sur les plus faibles, mais où chacun est prié de conserver suffisamment de valeurs spécifiques pour ne pas s'aliéner son voisin, ni être aliéné par lui. Au-delà de la position de principe, l'explication est intéressante parce qu'elle fait cas de la nécessité d'une lutte pour la survie de la différence ethnique, et pas seulement d'une position d'observateur fataliste, donc soumis aux déterminismes d'un horizon impensé. La cause de disparition n'est pas forcément rationnelle (1988 : 207-209). Lévi-Strauss défend le maintien de règles irrationnelles dans la conservation du système identitaire d'une ethnie. Il compare ainsi les règles sans fondement explicite de l'Académie française en les rapportant au fonctionnement d'un règlement intérieur de Collège d'Oxford. Une telle position en arrive fatalement à prôner une attitude volontariste, pour ne pas dire militante, dans la conservation de certains traits identitaires d'une culture, voire d'une ethnie. Dans tous ces cas de figures, la mort de l'ethnie est simplement retardée, plus qu'elle n'est suspendue ou définitivement écartée. Sa disparition est inéluctable, et elle est généralement pensée comme étant déjà passée du long terme au moyen terme, voire au court terme.

Dans le cas français, les ethnies se sont évaporées, remplacées par des réalités nationales, provinciales, départementales ou communales. Un lexique administratif a remplacé le lexique ethnique. Dans le cas africain, le vocabulaire politique colonial et postcolonial a découpé « artificiellement » les territoires nationaux en entités administratives qui ne recoupent pas les occupations « ethniques » antérieures, lesquelles se trouvent souvent à cheval sur les nouvelles frontières des États et des provinces. Les ethnies y subsistent "provisoirement ", mais leurs années sont comptées, même si leur poids électoral et parfois leur incidence réelle ou supposée sur des rapports de violence ne sont pas négligeables dans la période contemporaine. Enfin dans le cas wallisien, l'administration a superposé le découpage du territoire suivant les anciennes délimitations entre les entités villageoises en imposant le terme " district » 
à des portions de territoire dont on ne sait plus si elles étaient tribales ou non. Bref, disparue ou en voie de disparition, l'ethnie a symboliquement le statut d'une espèce en péril, vaincue par un déterminisme de type évolutionniste.

\section{UNE THÉORIE DE CYCLE ETHNIQUE RÉVERSIBLE}

Une quatrième solution théorique, et c'est celle que je suggérerai finalement - pour l'avoir également testée sur les terrains français, gabonais et wallisien - consisterait, pour cerner plus précisément ce qui produit la mort d'une ethnie, à donner ou redonner sens à tout ce qui la constitue. On ne prend pas seulement en compte le système causal de sa disparition, mais aussi le système causal de sa naissance et de ses transformations. Cette théorisation privilégie la notion de cycle, et envisage la production d'une ethnie au sein d'une théorie paléontologique mais aussi - et pourquoi pas? - au sein d'une société de l'époque industrielle. Si le principe du cycle est maintenu, alors on rend la répétition de l'ethnie possible, on rend sa reproduction possible, même dans un environnement " mondialisé ». À ce moment-là, l'ethnie est rapportée à une phylogenèse sociale reproductible. On pourrait croire que l'ethnie disparaît sans cause apparente, emportée par la modernité qui est exclusivement pensée comme une modernité occidentale. Or la pensée occidentale n'est qu'un accident de l'histoire, susceptible de changer en d'autres pôles décisionnels. Jack Goody rappelle que « l'alternance » est la moindre des précautions théoriques (1996:13). L'hégémonie occidentale sur l'histoire du monde n'a pas été permanente et elle n'est pas davantage vouée à être éternelle.

Cette nouvelle théorisation revient aussi de manière inattendue à une définition de la «culture » à laquelle on ne songerait pas, bien qu'elle plagie celle qu'un maire de Lyon, Édouard Herriot, avait imaginée pour la culture en général. De même que le précité faisait dire : "La culture, c'est ce qui reste quand on a tout oublié ", notre définition dirait : " La culture, c'est ce qui reste quand l'ethnie a disparu ou a été oubliée. " Notre perspective théorique se fonde donc comme la sienne sur une théorie de l'oubli. On est dans le pur socratisme! Ce n'est une fois encore pas qu'affaire de mots. Si nous sommes cohérents avec les tenants et aboutissants de cette théorie, alors nous devons instituer la notion de programme phylogénétique. Plus rigoureusement nous devons envisager toutes les étapes qui font passer de l'ethnie à la culture.

Dans ce cas de figure théorique, le concept d'ethnie est mis en équivalence terminale avec celui de culture. Au commencement théorique de la définition, nous aurions l'ethnie et dans son étape finale et résultante, nous aurions la culture. Dans notre conception, nous avons même forgé le concept intermédiaire d'" ethnoculture " (Mayer, 2003) pour identifier une étape-clé de transition et pour situer le moment-clé où une ethnie n'est plus tout à fait une ethnie sans être pour autant déjà une " culture ». En nous appuyant une fois encore sur l'exemple du Gabon, 
État africain à cinquante ethnies, nous nous rendons compte que les ethnies disparaissent à mesure que croît l'État et ses institutions territoriales. Ce remplacement par vases communicants s'amorce dès l'apparition de l'État colonial. Les premières mesures de l'État colonial consistent à instituer l'impôt de capitation, le travail forcé et à prétendre à une administration domaniale exclusive, en nommant en particulier les chefs de terre - autrement dit l'État s'impose dans la maîtrise absolue des domaines foncier, économique et politique qui relevaient auparavant de l'ethnie. On pourrait montrer que l'ethnoculture remplace l'ethnie, dès lors que celle-ci ne dispose plus de la maîtrise ni économique, ni politique du sol.

À une étape ultérieure, voyons ce qui distingue une ethnie d'une " culture ", ou si l'on préfère, plus radicalement, une non-ethnie. Notre premier constat fixe le principe qu'une ethnie ne disparaît jamais complètement, mais qu'il en reste toujours quelque chose. Les dénégations théoriques des ethnies se heurtent à l'observation quotidienne des mécanismes opératoires dans les "sociétés à ethnies" (opposables de ce fait à des "sociétés à cultures »). Notre deuxième principe désigne la culture comme terminus du processus de désagrégation d'une ethnie. Dans ce contexte, la culture n'a plus le sens holistique qu'on lui prête habituellement, mais au contraire un sens résiduel qui vise le terme d'un processus. C'est à la fois un sens dynamique et un sens réduit. Quelles sont les implications théoriques de ces deux constats?

Les implications du premier constat nous forcent à admettre que toute réflexion sur l'ethnie ne peut pas conclure sur une mort de l'ethnie, puisqu'il y a une après-mort de l'ethnie, et que tous les traits distinctifs ne s'éteignent pas définitivement. De plus, ils ne s'éteignent pas en même temps. Il faudra bien admettre des différences de rythmes évolutifs. Par exemple, les transformations technologiques sont plus rapides que les transformations de la parenté. Leroi-Gourhan (1964) a fort bien montré l'indépendance de la mutation technologique par rapport aux contraintes sociales pesant sur un groupe humain.

Les implications du deuxième constat nous forcent à préciser l'acception nouvelle qui est donnée au concept de «culture " dans le cadre explicatif ainsi créé. La culture n'est plus une donnée de départ, une donnée archaïque, mais une donnée d'arrivée, un résultat. C'est exactement le résultat d'une dynamique qui a eu pour origine une ethnie, et qui reste d'ailleurs une donnée dynamique à l'arrivée, le statisme du résultat n'étant que relatif à la finalité d'un processus premier qui est relayé par un processus nouveau, dès que le premier a trouvé son aboutissement.

Il y a donc le postulat que la disparition des ethnies est une " mort programmée ", presque une « euthanasie » qui n'aurait pas besoin d'être accompagnée d'une intervention de sauvegarde. Elle est moins une fatalité qu'une conséquence liée à l'évolution des sociétés. Certes «l'ethnocide » de Robert Jaulin a bien tenu le haut de l'affiche, mais il stigmatisait des situations exceptionnelles. Dans tous les cas de figures, les ethnies finissent par disparaître effectivement, mais en laissant des traces de leurs composantes constitutives, telles la maîtrise du sol ou la maîtrise des liens de parenté et d'alliance. Avant de disparaître de l'épistèmè 
scientifique, les ethnies laissent des pans entiers de leur constitution survivre sous des formes anciennes ou nouvelles.

La dynamique des changements culturels appelle ainsi une réflexion sur les antécédents et les conséquences des changements intervenus. Si nous prenons le modèle linguistique, nous arrivons à définir des étapes typées comme le « sabir ", le " créole », la « koinè » (Mouguiama, 2006). Avons-nous l'équivalent pour les « étapes de passage » de l'ethnie? Sous des concepts divers (syncrétisme, hybridation, métissage, choc culturel), les modalités des contacts influents ou non influents entre ethnies ont été proposées. Leur théorisation est pourtant loin d'être admise par une majorité de chercheurs.

\section{LA déCOMPOSITION DE l'ETHNIE COMME CULTURE RECOMPOSÉE}

Il nous faut donc reprendre ici la question laissée ouverte dans un précédent article consacré à la postmondialisation (2005), et qui se positionnait pour affirmer que dans le cadre de la mondialisation, il y avait à la fois un mouvement d'uniformisation et un mouvement de démultiplication des aspects d'une culture. Les exemples choisis concernaient certains domaines de la culture et permettaient de se faire une claire idée de l'évolution exponentielle, ou au contraire régressive, de certains secteurs de la culture. Cette démonstration vaut pour l'ethnie. Par exemple, on assiste à " la mort des langues ", à « la mort des lignages ", à « la mort des ethnies ", à l'uniformisation des technologies, à l'uniformisation des systèmes politiques, mais, parallèlement, on observe aussi une démultiplication des obédiences religieuses, une démultiplication des créations artistiques, une explosion des vecteurs de communication, quand bien même on peut assister en même temps à des concentrations industrielles et capitalistiques en ce domaine.

Il nous faut non seulement rendre compte de la coexistence du double phénomène, mais encore des facteurs déterminants de ces phénomènes apparemment contradictoires. Si l'on continue à accréditer la thèse d'une mondialisation par uniformisation, il faut expliquer pourquoi certains secteurs de la culture échappent à cette uniformisation et à cette " cristallisation ", ou au contraire intensifient leur diversification. Le concept rayonnant de la démonstration nous paraît être celui de l'individualisation ou de la non-individualisation des conditions de la production de la culture. Chaque fois qu'une décision dépend du seul individu, l'on s'achemine vers une multiplication des formes et des systèmes. Chaque fois au contraire, que le choix reste tributaire d'une instance supraindividuelle, il faut s'attendre à un renforcement des tendances uniformisantes du domaine. C'est la contradiction, somme toute seulement apparente, de la massification des moyens communs et de la liberté de choix de chacun. Ou la reconnaissance du " caractère dual » de l'ethnicité : «Celle-ci serait à la fois une donnée primordiale de l'existence humaine et l'objet de choix tactiques. » (Poutignat \& Streiff-Fenart, 1995)

Prenonsl'exemple de la religion. Celle-cia été pensée progressivement 
- mais non pas initialement - comme appartenant à la seule sphère individuelle. On est passé en France d'une conception "sociologique » (au sens primaire) de la religion, à celle d'une religion comme résultant du libre choix individuel. De la sorte, la religion rejoint le choix artistique : " des goûts et des couleurs on ne discute pas!". Cette formule sous-entend pourtant bien que l'on en discute au point d'en faire la possibilité d'une création aussi diversifiée qu'il y a d'individus. Dans le domaine artistique précisément, la création du concept d'arts premiers signifie justement que cet art n'entre pas dans les catégories de la création individuelle, mais seulement dans celles de la réception ou de la " lecture " individuelle de l'art, sous-entendu qu'elle dépend d'autant d'interprétations différenciées qu'il y a d'individus sur terre. L'inscription de ce libre choix dans la rédaction des chartes successives qui s'enchaînent et reflètent le consensus d'un univers mondialisé montre non pas l'universalité de fait des concepts, mais revendiquent leur universalité de droit. Malgré la maladresse des formulations ethnocentriques, celles-ci nous font au moins toucher du doigt que les questions évoluent et l'approche des domaines de la culture avec elles.

La démonstration est relativement simple sur la " mort des ethnies ", si l'on admet qu'une culture, c'est une ethnie qui a changé de système politique, de système religieux et de système linguistique, mais pas de système de parenté (et d'alliance). En prenant exemple sur le système européen, Maurice Godelier (2004 : 200) a montré comment les systèmes terminologiques de parenté étaient à l'abri d'une transformation dictée par un changement de régime politique et de régime économique. Le système terminologique « eskimo " qui caractérise les sociétés ouesteuropéennes n'a en effet pas varié, malgré la christianisation, malgré le passage d'une économie de subsistance à une économie féodale, puis capitaliste. Même si tout change, tout ne change pas en même temps.

La culture est le résultat de la décomposition d'une ethnie, en tant qu'œcumène de substitution. Encore convient-il de distinguer entre culture civilisationnelle, nationale, provinciale, locale et individuelle, bref entre différents états de ce qui est communément désigné aujourd'hui comme étant des "référents culturels ». Car, autant les quatre premières sphères d'insertion et de manifestation de la culture sont des facteurs conditionnant l'éducation et la vie active d'un individu - et donc en quelque sorte s'imposant à lui -, autant la culture individuelle est largement déterminée par le libre choix de celui-ci. Expression paradoxale qui dit bien la tension entre détermination passive et détermination active. Si dans ce dernier cas, il ne saurait être question d'une quelconque résultante ethnique, on doit convenir qu'une culture régionale ou provinciale ou locale est bien le résidu d'une ethnie. En ce sens, on vérifie qu'une ethnie ne meurt jamais tout à fait, et s'installe au contraire dans la longue durée imaginée par Leroi-Gourhan (1964).

S'agissant des relations entre " ethnie » et État, et plus particulièrement du passage de la première au second, on pourrait reprendre pour le compte de l'ethnie la problématique ouverte par Pierre Clastres (1972) au compte de la société. "L'ethnie contre l'État », tel pourrait être le titre adapté de l'ouvrage bien connu. De fait, l'organisation ethnique offre 
une alternative à l'organisation étatique, comme nous l'avons vu plus haut sur les exemples français, gabonais et wallisien. Comme semblent l'inférer également les cas corse, basque, yougoslave, irlandais, l'alternative " ethnique » n'est pas forcément unilatérale, même si elle apparaît alors comme un acte de résistance.

Nous pouvons considérer aussi qu'en tant qu'alternative maintenue parfois de façon violente, l'ethnie entre dans la dialectique potentielle de transformation des États, en particulier dans les politiques « démocratiques » de décentralisation. Les décentralisations pourraient être interprétées moins comme phénomènes identitaires que comme résurgence des ethnies dans un débat que l'on croyait périmé et définitivement enterré. Qu'est-ce à dire, sinon que l'ethnie est potentiellement immortelle? Il nous reste à déterminer quels sont les constituants immortels de l'ethnie, pour que ceux-ci parviennent à la faire survivre au-delà des siècles, quand bien même le schéma évolutionniste commun assigne à l'ethnie une disparition irréversible.

Parmi ces constituants, il nous faut incontestablement retenir les liens du sol et les liens du sang. Ce n'est pas un hasard si les mêmes constituants se retrouvent dans les critères familiers, et plus ou moins dosés, de la nationalité et de la citoyenneté dans les déclarations des États contemporains. Ce n'est pas pour rien que c'est l'expression " nations premières " (en parallèle à celle d'arts " premiers ") qui vient recouvrir l'indépendance recouvrée de peuples qui bénéficiaient de la primo-implantation dans un lieu donné avant sa colonisation des cinq derniers siècles. Il apparaît que ce n'est pas la liaison ethnie-sol qui constitue l'ethnie, mais la maîtrise du sol (transférée au cadastre dans la situation étatique), la maîtrise du pouvoir (transférée à un gouvernement externalisé dans la situation étatique) et la maîtrise des alliances (transférée à l'état civil dans la situation étatique). Toute théorie réinstaurant cette triple maîtrise rend la réversibilité possible.

\section{De la mORt de l'ethnie À la naissance de la culture}

Par voie de conséquence, si l'on va jusqu'au terme de la démonstration, on est obligé de convenir que la mort de l'ethnie signe l'acte de naissance de la culture. Celle-ci étant conçue comme une ethnie sans gestion de terre, sans pouvoir autonome, sans religion propre et sans langue spécifique. La culture est une ethnie d'où ont disparu les droits du sol, les droits du sang et les droits d'alliance, autrement dit une législation endogène. Il n'en reste que des vestiges matériels comme les styles « régionaux » de construction (colombages verticaux en Normandie, croisés en Alsace, toitures à pans inégaux au pays basque, chalet alpestre) ou mobiliers (rustique campagnard avec ses variantes typiques). On y ajoutera des éléments de patrimoine immatériel : croyances relatives à la cigogne en Alsace, aux puits hantés de Sologne, aux mares du diable du Berry, aux grottes de Dordogne; musiques et danses dites précisément «folkloriques » avec l'instrumentation qui s'y rattache. 
Faut-il identifier à ce niveau culture et folklore? Ce n'est pas certain, dans la mesure où dans toute culture déterritorialisée subsiste une part de culture " territorialisée ».

Une fois encore, Godelier a raison de dire que la christianisation des îles du Pacifique (mais le constat vaut pour toutes les portions de terres habitées de la planète) est un phénomène anthropologiquement plus important que ne le laissent paraître les centres de gravité de nos thèmes d'étude les plus courants. Cette première mondialisation idéologique a des conséquences directes sur le démembrement des ethnies. La culture est ainsi une réduction - quasiment au sens métallurgique - de l'ethnie, ou si l'on préfère, une ethnie sans pouvoir. On voit, ainsi, comment la disparition d'une ethnie permet d'identifier les critères de la constitution (presque au sens politique contemporain) d'une ethnie. La culture, c'est donc une ethnie qui a perdu son pouvoir régalien, ses droits du sol, sa religion et sa langue.

Curieusement, le système de parenté n'en fait pas partie, sinon comme système coextensif au pouvoir. L'ethnie disparaît quand le pouvoir n'est plus superposable aux liens de parenté. Dans les régimes monarchiques, ce trait a pu subsister au sein des lignées aristocratiques entretenant soigneusement leur réseau d'alliances endogame et se trouvant traumatisées à chaque liaison roturière non conforme au modèle établi. Qu'est-ce qui fait que le système de parenté échappe au cloisonnement ethnique? En Europe, il faut y voir la transformation des clans en dèmes et le passage du primat de la parenté sociale à la prééminence de la parenté biologique. Probablement aussi l'influence de la christianisation obligeant à l'exogamie jusqu'au septième degré de parenté (Vernier, 1999; Godelier, 2004) dans le système d'alliance généralisé ainsi promu. Autrement dit, la situation lignagère a cédé le pas devant la situation nucléaire renforcée par la monogamie définitivement instituée par obligation religieuse.

Si toutes ces considérations sur la transformation d'une ethnie en culture sont vraies, alors les reconstitutions en sens inverse devraient nous permettre de vérifier la réapparition d'une ethnie sur les fondements à rebours d'une culture. S'agit-il des « nouvelles ethnies » de Stuart Hall, des formes émergeantes de «l'autochtonie » de Françoise Morin (2005), des mouvements de résistance sécessionniste, de la balkanisation des fédérations, des tendances décentralisatrices des États fortement centralisés ou des principautés fossiles de nos États contemporains (Monaco, Andorre, Navarre, Lichtenstein, San Marino, voire le Luxembourg ou les cantons suisses)? Le champ d'application est suffisamment éclaté pour donner prise à de nombreuses observations relevant d'une conceptualisation de type ethnique ou d'analyses de type ethniste. Il n'est pas inconsidéré a priori de faire relever du champ ethnique des phénomènes aussi divers qui se situent tous à proximité du champ nationaliste. En opérant la jonction entre tribu, ethnie et nation chez les Baruya de Nouvelle-Guinée, Maurice Godelier (1985) n'avait pas craint d'associer des concepts généralement vus comme sans congruence entre eux. Or, les décompositions de nations et les recompositions d'ethnies obligent pourtant à prendre en compte ces concepts auparavant inconciliables sinon en position antagoniste et exclusive l'une de l'autre. 


\section{Conclusion}

Concluons sur la nuance de sens dont j'entoure le terme « ethnothanasie ». Dans les observations suggérées, l'ethnothanasie se définit bien comme une mise à mort de l'ethnie, mais à l'exemple de son cognat le plus proche - celui de "l'euthanasie »-, il s'agit bien d'une mise à mort lente, consensuelle et acceptée et non pas d'une mise à mort violente définie par les termes « ethnocide » et " génocide». C'est cette acception d'autodétermination qui rend la transformation non traumatisante. Depuis les années 1960, nous passons d'un modèle familial nucléaire à celui d'un modèle familial recomposé. Il ne viendrait à l'idée de personne de penser que ce nouveau modèle nous soit imposé par une puissance tierce, mais la nouvelle structuration familiale s'impose progressivement à toute la société, à toutes les familles et à tous les individus qui les composent sans que soit perçu un sentiment d'oppression extérieure. C'est, me semble-t-il, sur cette modélisation qu'il est possible de construire un schéma réversible de transformation de l'ethnie en culture, en admettant que le schéma est susceptible d'être réversible.

$\mathrm{Au}$ terme de ces quelques propositions théoriques pour penser la " mort des ethnies", nous pouvons afficher un cycle à trois termes où «l'ethnie » représente la première phase du processus de transformation et la « culture » sa phase ultime. La culture, c'est ce qui reste quand l'ethnie a disparu. En phase intermédiaire, «l'ethnoculture » apparaît dans le cours d'un processus transitoire voué à ne pas durer. Cette phase transitoire est essentiellement marquée par la perte de la maîtrise foncière et de la maîtrise politique, moins par la perte de la maîtrise linguistique et religieuse. La différence de rythme d'évolution de certains domaines par rapport à d'autres reste une question non résolue, tant par rapport à l'ethnie que par rapport à la culture.

\section{Références bibliographiques}

Amselle J.-L., 1990, Branchements, Paris, Flammarion, [1990] 2001.

— \& M'вокоцо E., Au coeur de l'ethnie. Ethnies, tribalisme et État en Afrique, Paris, La Découverte [1985] 1999.

Appadurai A., Après la colonisation. Les conséquences culturelles de la globalisation, [1996] trad. Paris, Payot, 2001.

AuGÉ M., Non-lieux. Introduction à une anthropologie de la surmodernité, Paris, Seuil, 1991.

Barth F., Ethnic Groups ans Boundaries: The Social Organization of Culture Difference, Boston, Brown and Co, 1969.

Clastres P., La société contre l'État, Paris, Seuil, 1972.

David-Néel A., Le vieux Tibet face à la Chine nouvelle, Paris, Plon, [1953] coll. Volumes, 1999.

DigARD J.P., " Compte-rendu sur Branchements de Jean-Louis Amselle », L'Homme, n 125, 1993, p. 164-165. 
Firth R., 1936, Nous, les gens de Tikopia, [1936] trad. Paris, Payot, 1974.

- Social change in Tikopia, Honolulu, Bernice Pauhi Bishop Museum Publications, 1959.

Franche D., "Généalogie du génocide rwandais, hutu et tutsi : Gaulois et Francs », Les temps modernes, n 582, 1995, p. 1-58.

Godelier M., «Ethnie, tribu, nation chez les Baruya de NouvelleGuinée », Journal de la Société des Océanistes, n 81, 1985, p. 159-168.

- Préface à La production des grands hommes chez les Baruya, Paris, Flammarion, coll. Champs, 1986.

- Métamorphoses de la parenté, Paris, Fayard, 2004.

Goody J., L'Orient en Occident, [1996] trad. Paris, Seuil, 1999.

JAUlin R.,L'ethnocide, Paris, PUF, 1970.

Leroi-Gourhan A., Milieu et technique, Paris, Seuil, 1964.

LÉvi-Strauss C., Race et histoire, Paris, unesco, 1952.

— "Culture et histoire " dans Anthropologie structurale deux, Paris, Plon, 1973.

- De près et de loin, Paris, Odile Jacob, 1986.

Malinowski B., Une théorie scientifique de la culture et autres essais, [1944] trad. Paris, Seuil/Points, 1970.

Malraux A., "Conférence de la salle Pleyel ", postface dans Les conquérants, Paris, Livre de Poche, 1965.

Martiniello M., L'ethnicité dans les sciences sociales contemporaines, Paris, PUF, coll. Que sais-je?, 1995.

Mayer R., Les transformations de la tradition narrative à l'île Wallis, Publications de la Société des Océanistes, n 38, 1976.

- Histoire de la famille gabonaise, Paris, Sépia, 1992.

— « De l'ethnie à l'ethnoculture ", Cahiers gabonais d'anthropologie, $\mathrm{n}^{\circ} 11,2003$, p. 1301-1312.

- «Anthropologie de la postmondialisation », Parcours anthropologiques, $\mathrm{n}^{\circ} 5,2005$, p. 24-34.

Mouguiama-Daouda P., Remplacement, extinction et mélanges de langues, Paris, L'Harmattan, 2006.

Morin F., « L'ONu comme creuset de l'autochtonie », Parcours anthropologiques, $\mathrm{n}^{\circ} 5,2005$, p. 35-41.

Poutignat Ph. \& Streiff-Fenart J., Théories de l'ethnicité, Paris, Puf, 1995.

Testard-Vaillant Ph., "Un héritage insignifiant ", Science et Vie, Hors série (la Gaule romaine), n 224, septembre 2003, p. 158-160.

Tonda J., « De l'ethnie », Cahiers gabonais d'anthropologie, n 12, 1999 (éd. 2001).

VALÉRY P., La crise de l'esprit, repris dans Variété III, Paris, Gallimard, 1919.

Vernier B., " Du nouveau sur l'inceste? Pour une théorie unitaire », La Pensée, n 318, 1999, p. 53-80. 